\title{
EFFECT OF ARGININE OR GLUTAMINE SUPPLEMENTATION ON PRODUCTION, ORGAN WEIGHTS, INTERFERON GAMMA, INTERLEUKIN 6 AND ANTIBODY TITRE OF BROILERS
}

\author{
József SZABÓ $^{1 *}$, Emese ANDRÁSOFSZKY ${ }^{1}$, Tamás TUBOLY ${ }^{2}$, András BERSÉNYI ${ }^{1}$, \\ Andrea WEISZ ${ }^{1}$, Nikoletta HETÉNYI ${ }^{1}$ and István HULLÁR ${ }^{1}$ \\ ${ }^{1}$ Institute for Animal Breeding, Nutrition and Laboratory Animal Science and \\ ${ }^{2}$ Department of Microbiology and Infectious Diseases, Faculty of Veterinary Science, \\ Szent István University, István u. 2, H-1078 Budapest, Hungary
}

(Received 4 January 2014; accepted 12 March 2014)

The objective of this study was designed to test whether supplementation of the diet with arginine (Arg) or glutamine (Gln) or their combination influences the production, organ weights and humoral immune response of broilers. A total of 432 one-day-old male Ross 308 broiler chickens were divided into 6 treatment groups: control, Arg- $0.5 \%$, Arg- $1 \%$, Gln- $0.5 \%$, Gln- $1 \%$ and Arg- $0.5 \%+\mathrm{Gln}-0.5 \%$. Drinking water and feed were provided ad libitum. On day 18 of the experiment $50 \%$ of chickens in each treatment group were immunised with bovine serum albumin. Ten and 21 days after immunisation blood samples were collected to determine the anti-albumin $\operatorname{IgY}$ titre, interleukin 6 (IL6) and interferon gamma (IFNG) and to measure the weight of the liver, spleen, bursa of Fabricius and thymus. Arg or Gln supplementation of the diets influenced neither the production nor the organ weights until 18 days of age. Between 18 and 39 days of age both $\operatorname{Arg}(0.5 \%$ and $1 \%)$ and $\mathrm{Arg}+\mathrm{Gln}$ supplementation improved the feed conversion ratio (FCR) by $3.7 \%, 6.3 \%$ and $4.9 \%$, respectively, while Gln- $1 \%$ worsened it by $15 \%$. Immunisation slightly $(-0.79 \%)$ depressed the body weight gain of broilers fed the control diet, which was significantly improved by both Arg (0.5 or 1\%) and Arg + Gln supplementation. Immunisation increased the weight of the spleen, bursa and thymus and decreased that of the liver. Supplementation with $1 \%$ Gln depressed $(-5.13 \%)$ the body weight gain of the immunised chickens but strongly stimulated the immune response. Supplementations with Arg and Gln did not influence the IL6 and IFNG level of the blood; however, on day 10 after immunisation these two parameters showed a negative correlation with each other. Regarding production, organ weights and immunity, Arg supplementation should be recommended in the grower phase, while Gln supplementation can be useful in pullets raised for egg production, where a good immune response to vaccinations is an important factor. IL6, IFNG

Key words: Arginine, glutamine, broilers, organ weights, antibody titre,

"Corresponding author; E-mail: szabo.jozsef@aotk.szie.hu; Phone: 0036 (1) 478-4126; Fax: 0036 (1) 478-4128 
After the ban of antibiotic growth promoters (AGPs) in the European Union (2006) there has been a need to identify and implement practical alternatives for AGPs to prevent infectious diseases and increase the production of broilers. Immunological intervention may be one of the useful possibilities to reduce microbial pathogens and improve the production parameters. Bioactive food components may interact with the immune response and increase the resistance of food-producing animals to infectious diseases. For example, some major classes of nutrients including amino acids such as arginine (Arg) (Kidd et al., 2001) and glutamine (Gln) (Soltan, 2009) may improve growth, performance, development of the gastrointestinal tract and the immune response.

Arginine is classified as a semi-essential amino acid, which functions as an intermediate in the urea cycle in several species and is a substrate for several compounds containing non-protein nitrogen. In chickens, dietary Arg is used only for the synthesis of protein and metabolically important molecules such as creatine. The metabolic Arg requirement of chickens does not include the urea cycle function because the main waste product of nitrogen metabolism in chicken is uric acid, the formation of which does not require Arg. It has also been shown that Arg is an essential amino acid for chickens (Arnold et al., 1936; Klose et al., 1938) because of the lack of detectable mitochondrial carbamoyl phosphate synthetase I enzyme in all tissues (Klose and Almquist, 1940). The Arg requirement of broilers is among the highest, due to the lack of endogenous synthesis and the high growth capacity. Under certain physiological or stress situations, dietary Arg may not be sufficient, and the consequence can be suboptimal weight gain and/or insufficient immune response to viral or bacterial antigens. Tayade et al. (2006) showed that Arg supplementation increased protection against infectious bursal disease virus challenge, showing the beneficial effect of this amino acid on immune functions. A similar observation has been reported by Munir et al. (2009) both for the humoral and the cellular immune response.

Glutamine is a non-essential amino acid, which accounts for $30-40 \%$ of the amino acids in the plasma (Newsholme et al., 1985). It is involved in protein, peptide and nucleic acid synthesis. Gln is distributed to the intestinal mucosa by arterial circulation and is a critical nitrogen source for rapidly dividing cells such as those of the intestinal mucosa, and may be the most important fuel for the mucosa (Wu, 1998). Supplementation of the diet with Gln may increase the length of villi in the small intestine (Soltan, 2009). Glutamine can act as an 'N shuttle', protecting the body from high levels of ammonia (Labow, 2001), and it is an important metabolic fuel in immune nutrition (Andrews and Griffiths, 2002; Li et al., 2007).

Since both Arg and Gln may be limiting regarding growth, performance and immune response in broilers, this study was designed to test whether supplementation of the diet with either of these two amino acids or their combination improves production (body weight, feed intake, feed/gain ratio), influences 
the weight of organs (liver, spleen, thymus and bursa of Fabricius) and the humoral immune response (anti-albumin IgY-titre, IL6 and IFNG levels) of broilers.

\section{Table 1}

Chemical composition of the diets

\begin{tabular}{lccc}
\hline Parameters & $\begin{array}{c}\text { Starter } \\
\text { (days 0-21) }\end{array}$ & $\begin{array}{c}\text { Grower } \\
\text { (days 22-35) }\end{array}$ & $\begin{array}{c}\text { Finisher } \\
\text { (days 36-39) }\end{array}$ \\
\hline AMEn (MJ/kg) & 13.1 & 13.1 & 13.5 \\
Dry matter (\%) & 90.0 & 89.9 & 90.4 \\
Ash (\%) & 6.04 & 6.37 & 6.23 \\
Crude protein (\%) & 22.8 & 20.0 & 17.6 \\
Ether extract (\%) & 3.03 & 4.54 & 4.93 \\
Crude fibre (\%) & 3.11 & 3.81 & 3.00 \\
\hline
\end{tabular}

Amino acid composition of the control diets (\%)

\begin{tabular}{lrrr} 
Lys & 1.45 & 1.13 & 1.03 \\
Met & 0.47 & 0.31 & 0.33 \\
Cys & 0.14 & 0.11 & 0.11 \\
Thr & 1.07 & 0.73 & 0.70 \\
Arg & 1.53 & 1.25 & 1.10 \\
Val & 0.75 & 0.54 & 0.50 \\
Ile & 0.73 & 0.53 & 0.51 \\
Leu & 2.41 & 1.58 & 1.50 \\
His & 0.59 & 0.46 & 0.43 \\
Asp & 2.62 & 2.04 & 1.86 \\
Ser & 1.44 & 1.04 & 0.95 \\
Glu + Gln & 4.23 & 3.33 & 3.05 \\
Gln & 0.46 & 0.39 & 0.33 \\
Pro & 1.68 & 1.07 & 1.07 \\
Gly & 1.05 & 0.80 & 0.73 \\
Ala & 1.42 & 0.94 & 0.90 \\
Tyr & 0.99 & 0.71 & 0.65 \\
Phe & 1.25 & 0.88 & 0.82 \\
$\Sigma$ & 23.84 & 17.47 & 16.25 \\
\hline
\end{tabular}

\section{Materials and methods}

A total of 432 one-day-old male Ross 308 broiler chickens were used. The birds were housed in an environmentally controlled room according to the standard broiler management practice of Ross (Ross Broiler Management Manual, Aviagen, 2009). The commercial broiler diets were purchased from Farmer-Mix Ltd. (Zsámbék, Hungary). L-arginine and glutamine (at least 99\% pure) were purchased from retail outlets. Feed and water were supplied ad libitum. The chemical composition (Table 1) of the diets used in the experiment was deter- 
mined according to the AOAC (1990) prescriptions. Amino acids of the diets were determined after acid hydrolysis by ion-exchange chromatography. Chromatography was performed using an AAA 400 amino acid analyser (Ingos Ltd., Czech Republic) equipped with an Ostion LG ANB ion-exchange column.

The chickens were randomly divided into 6 groups (72 birds per group), with 6 replicates (12 birds/replicate) in each dietary treatment group as indicated in Table 2. The experiment was divided into two phases. In phase one (from day 0 to day 18) the chickens were not immunised and in phase 2 (from day 19 to day 39) $50 \%$ of the broilers in each treatment group were immunised.

Table 2

Treatment groups used in the experiment

\begin{tabular}{|c|c|c|c|}
\hline \multirow{2}{*}{ Treatments } & Phase 1 (days 0-18) & \multicolumn{2}{|c|}{ Phase 2 (days 19-39) } \\
\hline & Starter (days 0-21) & Grower (days 22-35) & Finisher (days 36-39) \\
\hline Control & $\begin{array}{l}\text { Non-immunised } \\
12 \text { replicates }\end{array}$ & \multicolumn{2}{|c|}{$\begin{array}{l}\text { Non-immunised (Control) } \\
\text { Immunised (I-Control) }\end{array}$} \\
\hline Arg- $0.5 \%$ & $\begin{array}{l}\text { Non-immunised } \\
12 \text { replicates }\end{array}$ & \multicolumn{2}{|c|}{$\begin{array}{l}\text { Non-immunised (Arg-0.5\%) } \\
\text { Immunised (I-Arg-0.5\%) }\end{array}$} \\
\hline Arg- $1 \%$ & $\begin{array}{l}\text { Non-immunised } \\
12 \text { replicates }\end{array}$ & \multicolumn{2}{|c|}{$\begin{array}{l}\text { Non-immunised (Arg-1\%) } \\
\text { Immunised (I-Arg-1\%) }\end{array}$} \\
\hline Gln- $0.5 \%$ & $\begin{array}{l}\text { Non-immunised } \\
12 \text { replicates }\end{array}$ & \multicolumn{2}{|c|}{$\begin{array}{l}\text { Non-immunised (Gln-0.5\%) } \\
\text { Immunised (I-Gln-0.5\%) }\end{array}$} \\
\hline Gln-1\% & $\begin{array}{l}\text { Non-immunised } \\
12 \text { replicates }\end{array}$ & \multicolumn{2}{|c|}{$\begin{array}{l}\text { Non-immunised (Gln-1\%) } \\
\text { Immunised (I-Gln-1\%) }\end{array}$} \\
\hline $\mathrm{Arg}+\mathrm{G} \ln -0.5+0.5 \%$ & $\begin{array}{l}\text { Non-immunised } \\
12 \text { replicates }\end{array}$ & \multicolumn{2}{|c|}{$\begin{array}{l}\text { Non-immunised (Arg-0.5\%+Gln-0.5\%) } \\
\text { Immunised (I-Arg-0.5\%+Gln-0.5\%) }\end{array}$} \\
\hline
\end{tabular}

On day 18 of the experiment, chickens were marked with wing tags and $50 \%$ of them in each treatment group were immunised intraperitoneally $(100 \mu \mathrm{g}$ bovine serum albumin, BSA, in $200 \mu$ phosphate buffered saline, PBS, mixed with $200 \mu \mathrm{l}$ of incomplete Freund's adjuvant, Sigma-Aldrich) and the remaining birds served as non-immunised controls.

The individual body weights of the birds were measured on days 18,25 , 32 and 39. During phase 2, the total feed intake of replicates (6/treatment group) was recorded.

For monitoring the immune response, blood samples (18 samples from immunised and 18 from non-immunised chickens/treatment group) were collected from the ulnar vein at 18,28 and 39 days of age. The same wing-tagged chickens were used at each sampling time. Serum antibody titres were determined by standard ELISA protocols using BSA antigen and anti-chicken IgY-HRPO conjugate 
(SIGMA-Aldrich, 1:10,000). Interferon gamma (IFNG) and interleukin 6 (IL-6) levels were measured by the Chicken Interferon gamma and Chicken Interleukin 6 ELISA kits (Novatein Biosciences, Inc.) following the instructions of the manufacturer. Cytokine concentrations were expressed as $\mathrm{pg} / \mathrm{ml}$.

On day 18, 12 chickens and at the end of the experiment 6 immunised and 6 non-immunised chickens were randomly chosen from each treatment groups and exsanguinated under $\mathrm{CO}_{2}$ narcosis. The weight of the different organs (liver, spleen, thymus, bursa of Fabricius) was determined.

The results were expressed as arithmetic means $(\mathrm{AVG}) \pm \mathrm{SD}$ or in natural logarithm (LN) \pm SD. Statistical analysis of data was performed by one-way analysis of variance (ANOVA) with LSD post hoc multiple comparison test. The experimental protocol met the standard criteria of the Scientific Ethics Committee of Animal Experiments of the Faculty of Veterinary Science, Szent István University, Budapest, Hungary (registration number: 22.1/613/001/2010).

\section{Results and discussion}

\section{Effect of Arg or Gln on the body weight of 18-day-old birds (starter phase)}

The control starter diet contained $1.53 \%$ of Arg, $0.46 \%$ of Gln and $1.45 \%$ of Lys. The addition of Arg and/or Gln $(0.5 \%$ or $1 \%)$ to this starter diet did not influence the body weight significantly (Table 3), suggesting that the Arg or Gln contents of the control starter diet completely covered the Arg requirement of broilers during the first 18 days of life.

Labadan et al. (2001) suggested that, up to two weeks of age, breast muscle growth was the best when the starter diet contained 1.32\% Arg (crude protein content: $22 \%$ ) and $1.27 \%$ Lys. In our experiment, where the Arg/Lys ratio changed from 1:0.95 (control) to 1:0.71 (Arg-0.5\%) and 1:0.57 (Arg-1\%), the excess Arg relative to Lys did not induce any depression of body weight gain; however, an antagonism between Arg and excess Lys in the diet had been recognised in poultry (Kadirvel et al., 1974).

Contrary to our results, Bartell and Batal (2007) reported that, up to 21 days of age, $1 \%$ Gln supplementation improved the body weight gain of broilers compared with birds on a corn-soybean meal (SBM) diet. However, in pigs Kitt et al. (2002) also reported no improvement in body weight gain as a result of Gln supplementation of diet. We may speculate that the complexity of diets used in the different experiments, especially in terms of the protein sources in the diets (the Gln level of the basal diet), can be important factors regarding the differences noted. 


\section{Table 3}

Effect of immunisation on body weight, feed intake and feed conversion ratio of broilers fed diets supplemented with Arg or Gln from 18 to 39 days of age (different superscripts indicate significant difference at $\mathrm{P} \leq 0.05$ level)

\begin{tabular}{|c|c|c|c|c|c|c|c|}
\hline & & Control & Arg- $0.5 \%$ & Arg-1\% & Gln- $0.5 \%$ & Gln-1\% & Arg $+\mathrm{Gln}-0.5+0.5 \%$ \\
\hline & \multicolumn{7}{|c|}{ Day 18 (the end of the first experimental phase) } \\
\hline & $\mathrm{BW}, \mathrm{g}$ & $550.6 \pm 64.7$ & $554.5 \pm 47.8$ & $552.2 \pm 50.9$ & $551.0 \pm 43.4$ & $544.2 \pm 63.3$ & $524.1 \pm 49.5$ \\
\hline \multicolumn{8}{|c|}{ Day 18 (the first day of the second phase) Average body weight of broilers after the random distribution into immunised and non-immunised groups } \\
\hline \multirow{2}{*}{ Non-immunised } & BW, g & $557.2 \pm 68.4$ & $551.4 \pm 47.7$ & $549.9 \pm 56.5$ & $555.6 \pm 42.8$ & $537.1 \pm 64.5$ & $522.1 \pm 51.6$ \\
\hline & $(\%)$ & $100.0 \pm 12.3$ & $100.0 \pm 8.65$ & $100.0 \pm 10.3$ & $100.0 \pm 7.71$ & $100.0 \pm 12.01$ & $100.0 \pm 9.9$ \\
\hline \multirow[t]{2}{*}{ Immunised } & BW, g & $537.4 \pm 56.2$ & $560.7 \pm 48.7$ & $554.3 \pm 40.0$ & $539.7 \pm 44.0$ & $561.3 \pm 57.3$ & $528.1 \pm 46.2$ \\
\hline & $(\%)$ & $100.0 \pm 10.5$ & $100.0 \pm 8.7$ & $100.0 \pm 7.2$ & $100.0 \pm 8.2$ & $100.0 \pm 10.2$ & $100.0 \pm 8.8$ \\
\hline \multirow{3}{*}{ Non-immunised } & & & & Day 25 & & & \\
\hline & BW, g & $968.7 \pm 116.1$ & $989.0 \pm 78.0$ & $998.5 \pm 109.2$ & $997.4 \pm 121.8$ & $932.1 \pm 118.1$ & $972.2 \pm 106.4$ \\
\hline & $(\%)$ & $173.9^{\mathrm{a}} \pm 20.8$ & $179.4^{\mathrm{ab}} \pm 14.2$ & $181.6^{\mathrm{ab}} \pm 19.8$ & $179.5^{\mathrm{a}} \pm 21.9 \mathrm{a}$ & $173.6^{\mathrm{a}} \pm 22.0$ & $186.2^{\mathrm{b}} \pm 20.4$ \\
\hline \multirow[t]{2}{*}{ Immunised } & BW, g & $939.7 \pm 135.5$ & $1015.5 \pm 85.1$ & $1014.8 \pm 93.0$ & $962.8 \pm 90.4$ & $943.4 \pm 95.9$ & $975.9 \pm 95.1$ \\
\hline & $(\%)$ & $174.9^{\mathrm{ab}} \pm 25.2$ & $181.1^{\mathrm{b}} \pm 15.2$ & $183.1^{\mathrm{b}} \pm 16.8$ & $178.4^{\mathrm{b}} \pm 16.7$ & $168.1^{\mathrm{a}} \pm 17.1 \mathrm{a}$ & $184.8^{\mathrm{b}} \pm 18.0$ \\
\hline \multirow{3}{*}{ Non-immunised } & & & & Day 32 & & & \\
\hline & $\mathrm{BW}, \mathrm{g}$ & $1550.3 \pm 159.9$ & $1601.6 \pm 117.3$ & $1594.4 \pm 163.3$ & $1563.6 \pm 170.5$ & $1509.3 \pm 177.3$ & $1529.5 \pm 147.5$ \\
\hline & $(\%)$ & $278.2^{\mathrm{a}} \pm 28.7$ & $290.4^{\mathrm{b}} \pm 21.3$ & $289.9^{\mathrm{ab}} \pm 29.7$ & $281.4^{\mathrm{a}} \pm 30.7$ & $281.0^{\mathrm{ab}} \pm 33.0$ & $292.9^{b} \pm 28.2$ \\
\hline \multirow[t]{2}{*}{ Immunised } & BW, g & $1483.4 \pm 183.1$ & $1619.6 \pm 118.6$ & $1627.2 \pm 142.2$ & $1530.9 \pm 165.0$ & $1496.9 \pm 157.1$ & $1563.8 \pm 152.8$ \\
\hline & $(\%)$ & $276.0^{\mathrm{ab}} \pm 34.1$ & $288.8^{\mathrm{ab}} \pm 21.2$ & $293.6^{\mathrm{ab}} \pm 25.7$ & $283.6^{\mathrm{ab}} \pm 30.6$ & $266.7^{\mathrm{a}} \pm 28.0$ & $296.1^{b} \pm 28.9$ \\
\hline \multirow{3}{*}{ Non-immunised } & & & & Day 39 & & & \\
\hline & BW, g & $2138.8 \pm 191.1$ & $2240.8 \pm 186.1$ & $2200.8 \pm 175.4$ & $2130.9 \pm 247.5$ & $2104.0 \pm 232.6$ & $2144.6 \pm 194.3$ \\
\hline & $(\%)$ & $383.8^{\mathrm{a}} \pm 34.3$ & $406.4^{\mathrm{bc}} \pm 33.7$ & $400.2^{\mathrm{bc}} \pm 31.9$ & $383.5^{\mathrm{a}} \pm 44.5$ & $391.7^{\mathrm{ab}} \pm 43.3$ & $410.8^{\mathrm{c}} \pm 37.2$ \\
\hline \multirow[t]{2}{*}{ Immunised } & BW, g & $2046.6 \pm 228.1$ & $2284.1 \pm 190.5$ & $2255.8 \pm 204.0$ & $2114.5 \pm 232.7$ & $2041.6 \pm 227.8$ & $2201.6 \pm 203.3$ \\
\hline & $(\%)$ & $380.8^{\mathrm{a}} \pm 42.4$ & $407.4^{\mathrm{b}} \pm 34.0$ & $407.0^{b} \pm 36.8$ & $391.7^{\mathrm{b}} \pm 43.1$ & $363.7^{\mathrm{a}} \pm 40.6$ & $416.9^{\mathrm{b}} \pm 38.5$ \\
\hline \multicolumn{8}{|c|}{ Days 18-39 (non-immunised and immunised together) } \\
\hline Feed intake & (g/day/chicken) & $137.3 \pm 8.79$ & $139.9 \pm 5.36$ & $142.5 \pm 3.37$ & $139.9 \pm 5.42$ & $135.8 \pm 4.63$ & $141.5 \pm 0.06$ \\
\hline FCR & $(\mathrm{kg} / \mathrm{kg})$ & $1.84^{\mathrm{ab}} \pm 0.14$ & $1.74^{\mathrm{a}} \pm 0.06$ & $1.83^{\mathrm{a}} \pm 0.08$ & $1.88^{\mathrm{bc}} \pm 0.09$ & $1.97^{\circ} \pm 0.12$ & $1.77^{\mathrm{a}} \pm 0.07$ \\
\hline
\end{tabular}


Effect of Arg or Gln supplementation on the body weight of broilers between 18 and 39 days of age

In the second phase of the experiment each of the treatment groups was randomly divided into two subgroups (immunised and non-immunised). To diminish the slight starting body weight differences among the treatment groups, the body weights of chickens on day 18 were regarded as $100 \%$.

In the non-immunised broilers both the $0.5 \%$ and $1 \%$ Arg and the Arg$0.5 \%+$ Gln- $0.5 \%$ supplementations significantly increased the body weight (by $5.9,4.3 \%$ and $7.0 \%$, respectively) (Fig. 1), suggesting that the Arg level of the control grower and finisher diets was not sufficient for the maximum growth of broilers in the second phase of the experiment (days 18 to 39).

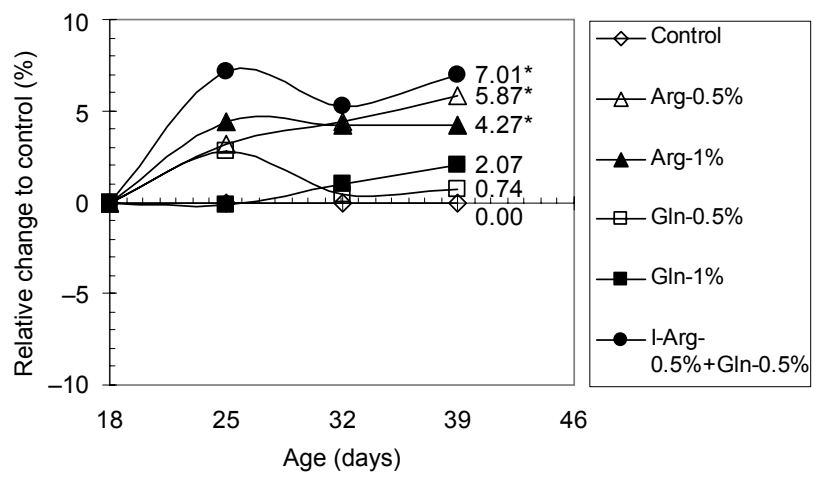

Fig. 1. Time-related effect of diets supplemented with arginine (Arg) and/or glutamine (Glu) on the body weight of broilers $(*=$ the difference from the control is significant at $\mathrm{P} \leq 0.05$ level $)$

On the basis of our results, around $1.7 \%$ Arg in the grower diet may be the optimum level, when the protein and Lys content of the diet were $19.7 \%$ and $1.13 \%$, respectively. This Arg level is much higher than the requirement found by Labadan et al. (2001) (1.16\% Arg and $1.15 \%$ Lys) for 3- to 6-week-old broilers. We suggest that, in order to attain the best performance of 3- to 6-week-old Ross 308 broilers, the Arg/Lys ratio should be positive, 1.4 to 1.0 , at $1.15 \%$ Lys level in the diet.

During the same treatment period, $0.5 \%$ Gln supplementation did not induce any significant effect on the body weight gain of non-immunised broilers; however, $1 \%$ Gln supplementation slightly but not significantly $(+2.07 \%)$ increased the body weight of the non-immunised chickens by the end of the experiment.

Soltan (2009) reported that by the end of the 6th week the body weight of a broiler chicken group receiving $1 \%$ Gln supplementation was significantly higher than that of the control. Higher Gln supplementation (1.5 and 2\%) did not induce any significant change relative to the control group. On the other hand, Bartell and Batal (2007) found that by day 14, 1\% Gln supplementation im- 
proved the body weight gain compared to birds fed a standard corn-soybean meal diet. Conversely, 4\% Gln supplementation to the diet depressed the performance of chickens. As the 4\% Gln supplementation level is much higher than the estimated no-observed-adverse-effect level (NOAEL) (Tsubuku et al., 2004) for Gln (1.25\% for rats), it can be supposed that this negative effect may be the result of Gln toxicity. Based on the data reported by others and our data presented here, Gln supplementation levels higher than $1 \%$ are not recommended in broiler diets; however, this may depend on the Gln content of the basal diet.

Effect of immunisation and Arg or Gln supplementation on the body weight of broilers between 18 and 39 days of age

In the second phase of the experiment ( 3 to 6 weeks), immunisation slightly depressed the growth of broilers $(-0.79 \%)$ receiving the control diet; however, these differences were not statistically significant (Fig. 2). When the diets of immunised chickens were supplemented with Arg (0.5 or 1\%), Gln $(0.5 \%)$ or with the combination of Arg and Gln $(0.5 \%+0.5 \%)$, the immunisation induced a slight growth depression which was then not only compensated but turned into a positive direction.

These immunised chickens grew as well as, or even better (by $6.33 \%$, $6.13 \%, 2.07 \%$ and $8.60 \%$ in the I-Arg- $1 \%$, I-Arg- $0.5 \%$, I-Gln- $0.5 \%$ or Arg- $0.5 \%$ + Gln- $0.5 \%$ groups, respectively) than the non-immunised chickens receiving the same diet (Arg-0.5\%: 5.87\%, Arg-1\%: 4.27\%, Gln-1\%: 2.07\% and Arg-0.5\% + Gln- $0.5 \%: 7.04 \%$ ) (Fig. 2). This suggests that the immunisation itself stimulates the protein turnover of the animals. Garlick et al. (1980) noted a 37\% increase in protein synthesis and a 55\% increase of protein degradation after vaccination. We may assume that the higher Arg levels of the supplemented diets covered the immunisation-generated extra amino acid and/or energy requirement of the immune system.

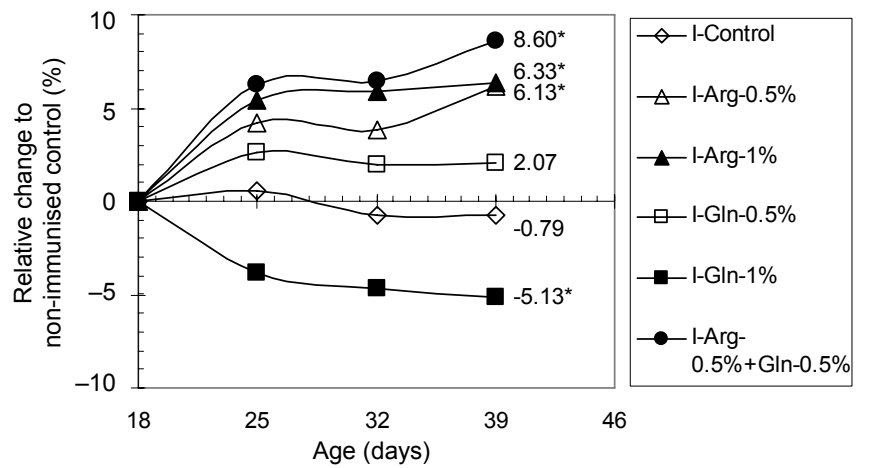

Fig. 2. Time-related effect of immunisation on the body weight of broilers fed Arg- and/or Gln-supplemented diets $\left(^{*}=\right.$ the difference from the control is significant at $\mathrm{P} \leq 0.05$ level) 
It is interesting that in the non-immunised broilers the higher (1\%) and in the immunised chickens the lower $(0.5 \%)$ dose of Gln supplementation induced a slight $(2.07 \%)$ but not significant increase in body weight. Contrary to this, $1 \%$ Gln supplementation significantly $(\mathrm{P}<0.05)$ depressed $(-5.13 \%)$ the body weight gain of the immunised chickens (Fig. 2); moreover, this depression was significantly stronger $(-5.13 \%)$ than in chickens of the I-Control group $(-0.79 \%)$. The statistical analysis clearly shows that there was a strongly significant difference between the immunised and non-immunised chickens regarding Gln on the body weight.

We suggest that this negative effect was in accordance with the magnitude of the immune response, which was significantly higher in the I-Gln-1\% group than in the I-Control animals (Table 5). This is in accordance with the findings that Gln is required for lymphocyte proliferation (Wu et al., 1992) in a dose-dependent manner and it is catabolised by the glutaminolytic pathway to yield glutamate and other metabolites for cells of the immune system, including thymocytes, blood lymphocytes, intraepithelial lymphocytes, neutrophils and macrophages ( $\mathrm{Li}$ et al., 2007). Because the Gln derived from the diet is almost completely utilised by cells of the intestine, the Gln necessary for the extraintestinal lymphocytes and other rapidly dividing cells may come from the amino acid metabolism in muscles (Newsholme et al., 1985). If the body uses more glutamine than it can produce (i.e. during times of increased immune reactions), muscle wasting can occur because muscle is the primary site for Gln. This can be an explanation for the slight growth depression observed after immunisation.

\section{Effect of dietary Arg or Gln supplementation on feed intake and feed conversion ratio (FCR) between 18 to 39 days of age in broilers}

Because immunised and non-immunised chickens were housed and fed together in each treatment group, the feed intake and consequently the FCR were not determined separately. Table 3 indicates the effect of Arg or Gln supplementation on feed intake of the mixed (immunised and non-immunised) populations of chickens.

The supplementation of grower and finisher diets with Arg or Gln or with the combination thereof did not influence the feed intake significantly. Regarding Arg, our result is different from the findings of Al-Daraji and Salih (2012), who reported that Arg supplementation $(0.02 \%, 0.04 \%$ and $0.06 \%$ of the diet $)$ significantly increased the feed intake of broilers. An explanation of these conflicting results may be the 10 and 20 times higher levels $(0.5 \%$ and $1.0 \%)$ of supplementation used in the current study. Another confounding factor may be that the feed intakes of immunised and non-immunised chickens were not determined separately. However, data reported by others indicate that immunisation did not influence the feed intake and FCR of broilers (El-Sayed et al., 2011). In an experiment with pigs, Hagemeier et al. (1983) studied the effect of three Arg levels $(0.94 \%, 1.29 \%$ and $1.63 \%)$ similar to the doses used in our study, and they found that Arg had no effect on the daily feed intake. 
Table 4

Effect of Arg or Gln supplementation of the diets on organ weights of immunised chickens (different superscripts indicate significant difference at $\mathrm{P} \leq 0.05$ level)

\begin{tabular}{lccccccc}
\hline & NI-Control & \multicolumn{1}{c}{ I-Control } & I-Arg-0.5\% & I-Arg-1\% & I-Gln-0.5\% & I-Gln-1\% & $\begin{array}{c}\text { I-Arg }+ \text { Gln- } \\
0.5+0.5 \%\end{array}$ \\
\cline { 2 - 8 } & & & \multicolumn{1}{c}{$(\mathrm{g} / 100 \mathrm{~g} \mathrm{BW})$} \\
\hline Liver & $2.16^{\mathrm{b}} \pm 0.19$ & $1.86^{\mathrm{a}} \pm 0.16$ & $2.11^{\mathrm{b}} \pm 0.05$ & $2.23^{\mathrm{b}} \pm 0.33$ & $2.10^{\mathrm{ab}} \pm 0.27$ & $2.15^{\mathrm{b}} \pm 0.14$ & $1.98^{\mathrm{ab}} \pm 0.18$ \\
Spleen & $0.089^{\mathrm{ab}} \pm 0.018$ & $0.104^{\mathrm{ab}} \pm 0.028$ & $0.094^{\mathrm{ab}} \pm 0.014$ & $0.074^{\mathrm{a}} \pm 0.023$ & $0.114^{\mathrm{b}} \pm 0.027$ & $0.107^{\mathrm{ab}} \pm 0.033$ & $0.085^{\mathrm{ab}} \pm 0.025$ \\
Thymus & $0.137^{\mathrm{a}} \pm 0.023$ & $0.163^{\mathrm{ab}} \pm 0.041$ & $0.200^{\mathrm{b}} \pm 0.044$ & $0.153^{\mathrm{ab}} \pm 0.035$ & $0.180^{\mathrm{ab}} \pm 0.017$ & $0.199^{\mathrm{b}} \pm 0.027$ & $0.162^{\mathrm{ab}} \pm 0.073$ \\
Bursa of Fabricius & $0.215^{\mathrm{a}} \pm 0.027$ & $0.315^{\mathrm{b}} \pm 0.042$ & $0.237^{\mathrm{a}} \pm 0.024$ & $0.262^{\mathrm{ab}} \pm 0.055$ & $0.249^{\mathrm{ab}} \pm 0.081$ & $0.346^{\mathrm{b}} \pm 0.122$ & $0.242^{\mathrm{ab}} \pm 0.056$ \\
\hline
\end{tabular}

Table 5

Effect of Arg or Gln on anti-albumin IgY-titre, IL-6 and IFNG level of immunised chickens (different superscripts indicate significant difference at $\mathrm{P} \leq 0.05$ level) 
Bartell and Batal (2007) reported that the effect of Gln on the FCR was not consistent. One percent Gln supplementation decreased but 4\% Gln supplementation increased the FCR. In our experiment there was a significant difference between the Arg- and Gln-supplemented groups in terms of FCR. While Arg and the combination of Arg and Gln slightly but not significantly decreased (improved), Gln-1\% significantly increased (worsened) the FCR (Table 3) between 18 and 39 days of age. Based on the body weight gain, feed intake and FCR data, $1.7 \%$ Arg in the grower diet (1.25\% original Arg level $+0.5 \%$ Arg supplementation) resulted in the best production parameters. Because Arg is a potent secretagogue for insulin (Newsholme et al., 2005), growth hormone and insulinlike growth factor, and it also stimulated the body weight gain and improved the feed efficiency of both non-immunised and immunised broilers, we propose that Arg is a potent growth promoter for broilers and the supplementation of grower diets with Arg should be incorporated in the poultry nutrition practice.

\section{Effect of dietary Arg or Gln supplementation on the organ weights of broilers}

Arg or Gln supplementations did not induce any significant change in organ weights during the first phase of the experiment. This result is in agreement with the data of Deng et al. (2003), i.e. that low $(0.67 \%$; $70 \%$ of the NRC recommendations) or high $(1.21 \% ; 130 \%$ of the NRC recommendations; National Research Council, 1994) dietary Arg levels did not induce any significant differences in the weight of organs (either lymphoid or non-lymphoid tissues) during the starter phase. In contrast to this, Kwak et al. (1999) reported that Arg markedly influenced the development of lymphoid organs, with a more pronounced effect on the thymus and spleen than on the bursa of Fabricius. They reported that an Arg-deficient diet reduced the body weight gain and the weights of the thymus, spleen and bursa of Fabricius. A small (0.2\%) dietary Arg supplementation (at $0.73 \%$ dietary Arg level) was sufficient to support the development of body and lymphoid organs of chickens.

In the second phase of our experiment (days 18-39), in chickens fed the control diet, the immunisation significantly $(\mathrm{P}<0.05)$ decreased the weight of the liver (Table 4, Fig. 3). On the other hand, the weight of the bursa of Fabricius was significantly higher than in the control birds. The weights of spleen and thymus tended to be higher than in the non-immunised control birds; however, these increases were not significant. These results suggest that in the immunised animals a higher proportion of the dietary amino acids and energy was used in the lymphoid organs and less were supplied to the liver.

The data presented in Table 4 indicate that the elevated dietary Arg level (Arg-1\%) decreased the effect of immunisation on the organs studied. The weights of the liver were significantly $(\mathrm{P}<0.05)$ higher while the weight of the bursa of Fabricius was lower than in the immunised birds fed the control diet. Gln and Arg supplementation induced similar weight changes in the liver. The 
effect of Gln on the lymphoid organs was not significant. The effect of Arg on the lymphoid organs depended on the dose and the organ (Arg-1\% decreased the weight of the spleen and Arg- $0.5 \%$ increased the weight of thymus significantly).

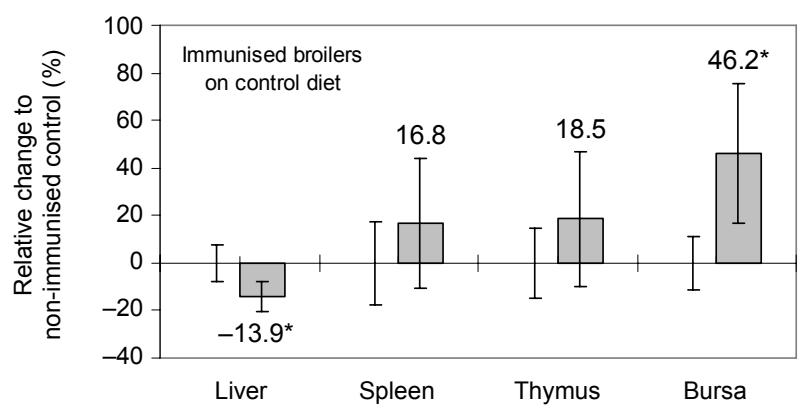

Fig. 3. Effect of immunisation on organ weights of broilers $(*=$ the difference from the control is significant at $\mathrm{P} \leq 0.05$ level)

Effect of Arg or Gln supplementation of the diets on the anti-albumin IgY titre as well as IL-6 and IFNG levels of broilers

As compared to the control, both Arg and Gln supplementation increased the antibody titres; however, the increase was significant only for the Gln-1\% group $(\mathrm{P}<0.05) 10$ days after the immunisation. By the end of the experiment the antibody titre decreased in each treatment group (Table 5).

The anti-albumin IgY titre clearly followed the general primary humoral immune response. The differences in these antibody levels detected at the two time-points of sampling indicated that both Arg and Gln supplementation increased the specific immune response to the given antigen, resulting in not only a stronger but also a longer-lasting protection.

The IL-6 and IFNG data showed a negative correlation 10 days after immunisation $(\mathrm{R}=-0.726)$. This result is not surprising since IFNG is well known to decrease $\mathrm{T}$ helper (Th) 2 type cytokine production (Schroder et al., 2004) including IL-6 synthesis.

Based on the results presented above it can be concluded that, during the starter phase, Arg or Gln supplementation of the diets influenced neither the production parameters nor the organ weights until 18 days of age, suggesting that the Arg and Gln content of the starter diet adequately covered the requirements of Ross 308 broilers. In the grower and finisher phases (days 19-39), both Arg $(0.5$ and $1 \%)$ and the Arg + Gln supplementation of the diets significantly improved the production parameters, suggesting that the Arg requirement of the Ross 308 broilers in that production period is higher than the recommended $1.2 \%$ level.

The slight depression of growth induced by immunisation was not only compensated but turned into a positive direction by $\operatorname{Arg}(0.5 \%$ or $1 \%)$, Gln 
$(0.5 \%)$ or $\mathrm{Arg}+\mathrm{Gln}(0.5+0.5 \%)$ supplementation of the grower and finisher diets. The addition of $1 \%$ Gln supplementation significantly $(\mathrm{P}<0.05)$ depressed $(-4.49 \%)$ the body weight gain of the immunised chickens. Supplementation of the grower and finisher diets with $1 \%$ Gln stimulated the immune response very effectively; however, the body weight gain was significantly lower than in the non-immunised and immunised control groups.

In the grower and finisher phases, immunisation significantly $(\mathrm{P}<0.05)$ decreased the weight of the liver; however, the weights of the thymus and the bursa of Fabricius were higher than in the control birds. Measurements of cytokine levels indicated that 10 days after the immunisation there was a significant negative correlation between IL-6 and IFNG. Regarding production, organ weights and immunity, Arg supplementation should be recommended in the grower phase; Arg seemed to be a good growth promoter for both the immunised and the control birds. Gln supplementation can be useful in pullets raised for egg production, where a good immune response to vaccinations is an important factor.

\section{Acknowledgement}

This work was sponsored by grant NKB $15735 / 2012$ of the Faculty of Veterinary Science, Szent István University, Budapest, Hungary.

\section{References}

Al-Daraji, H. J. and Salih, A. M. (2012): Effect of dietary L-arginine on productive performance of broiler chickens. Pakistan J. Nutr. 11, 252-257.

Andrews, F. J. and Griffiths, R. D. (2002): Glutamine: Essential for immune nutrition in the critically ill. Br. J. Nutr. 87, S3-S8.

AOAC (1990): Official Methods of Analysis, 15th edition. Association of Official Analytical Chemists, Washington, D.C. pp. 69-82.

Arnold, A., Kline, O. L., Elvehjem, C. A. and Hart, E. B. (1936): Further studies on the growth factor required by chicks. The essential nature of arginine. J. Biol. Chem. 116, 699-709.

Aviagen Limited (2009): ROSS Broiler Management Manual. Aviagen Limited.

Bartell, S. M. and Batal, A. B. (2007): The effect of supplemental glutamine on growth performance, development of gastrointestinal tract, and humoral immune response of broilers. Poult. Sci. 86, 1940-1947.

Deng, K., Wong, C. W. and Nolan, J. V. (2003): Carryover effects of dietary L-arginine on the immune system in chickens. Rec. Adv. Anim. Nutr. Austr. 14, 8A.

El-Sayed, D. A. A., Abdou, A. M., Shalash, S. M. M., Safaa, H. M. and Riad, S. A. (2011): Productivity and immune response of broiler chickens vaccinated with different avian influenza vaccines at one or seven days of age. Aust. J. Basic Appl. Sci. 5, 325-334.

Garlick, P. J., McNurlan, M. A., Feern, E. B., Tomkins, A. M. and Waterlow, J. C. (1980): Stimulation of protein synthesis and breakdown by vaccination. Br. Med. J. 26, 263-265.

Hagemeier, D. L., Libal, G. W. and Wahlstrom, R. C. (1983): Effect of excess arginine on swine growth and plasma amino acids. J. Anim. Sci. 57, 99-105.

Kadirvel, R., Vohra, P. and Kratzer, F. H. (1974): Arginine, lysine and glycine interaction in the nutrition of chick. J. Nutr. 104, 1127-1134. 
Kidd, M. T., Peebles, E. D., Whitmarsh, S. K., Yeatman, J. B. and Wideman, R. F. (2001): Growth and immunity of broiler chicks as affected by dietary arginine. Poult. Sci. 80, 1535-1542.

Kitt, S. J., Miller, P. S., Lewis, A. J. and Fisher, R. L. (2002): Effects of glutamine on growth performance and small intestine villus height in weanling pigs. Nebraska Swine Rep., University of Nebraska, Lincoln. pp. 29-32.

Klose, A. A. and Almquist, H. J. (1940): The ability of citrulline to replace arginine in the diet of chick. J. Biol. Chem. 135, 153-155.

Klose, A. A., Stokstad, E. L. R. and Almquist, H. J. (1938): The essential nature of arginine in the diet of the chick. J. Biol. Chem. 123, 691-698.

Kwak, H., Austic, R. E. and Dietert, R. R. (1999): Influence of dietary arginine concentration on lymphoid organ growth in chickens. Poult. Sci. 78, 1536-1541.

Labadan, M. C. Jr., Hsu, K. N. and Austic, R. E. (2001): Lysine and arginine requirements of broiler chickens at two- to three-week intervals to eight weeks of age. Poult. Sci. 80, 599-606.

Labow, B. L. (2001): Mechanisms governing the expression of the enzymes of glutamine metabolism - glutaminase and glutamine synthetase. J. Nutr. 131, 2467-2474.

Li, P., Yin, Y. L., Li, D., Kim, S. W. and Wu, G. (2007): Amino acids and immune function. Br. J. Nutr. 98, 237-252.

Munir, K., Muneer, M. A., Masaoud, E., Tiwari, A., Mahmud, A., Chaudhry, R. M. and Rashid, A. (2009): Dietary arginine stimulates humoral and cell-mediated immunity in chickens vaccinated and challenged against hydropericardium syndrome virus. Poult. Sci. 88, 1629-1638.

National Research Council (1994): Nutrient Requirements of Poultry. 9th revised edition. National Academy Sciences, Washington, D.C. pp. 26-34.

Newsholme, E. A., Crabtree, B. and Ardawi, M. S. M. (1985): Glutamine metabolism in lymphocytes: its biochemical, physiological and clinical importance. Quart. J. Exp. Physiol. 70, 473-489.

Newsholme, P., Brennan, L., Rubi, B. and Maechler, P. (2005): New insight into amino acid metabolism, beta-cell function and diabetes. Clin. Sci. 108, 185-194.

Schroder, K., Hertzog, P. J., Ravasi, T. and Hume, D. A. (2004): Interferon-gamma: an overview of signals, mechanisms and functions. J. Leukoc. Biol. 75, 163-189.

Soltan, M. A. (2009): Influence of dietary glutamine supplementation on growth performance, small intestinal morphology, immune response and some blood parameters of broiler chickens. Int. J. Poult. Sci. 8, 60-68.

Tayade, C., Jaiswal, T. N., Mishra, S. C. and Koti, M. (2006): L-arginine stimulates immune response in chickens immunized with intermediate plus strain of infectious bursal disease vaccine. Vaccine 24, 552-560.

Tsubuku, S., Hatayama, K., Mawatari, K., Smriga, M. and Kimura, T. (2004): Thirteen-week oral toxicity study of L-glutamine in rats. Int. J. Toxicol. 23, 107-112.

Wu, G. (1998): Intestinal mucosal amino acid catabolism. J. Nutr. 128, 1249-1252.

Wu, G., Field, C. J. and Marlis, E. B. (1992): Enhanced glutamine and glucose metabolism in cultured rat splenocytes stimulated by phorbol myristate acetate plus ionomycin. Metabolism 41, 982-988. 